\title{
Review Article \\ Recurrence and Treatment after Renal Transplantation in Children with FSGS
}

\author{
Hee Gyung Kang, ${ }^{1,2}$ Il-Soo $\mathrm{Ha}^{1,3}$ and Hae Il Cheong ${ }^{1,2,3}$ \\ ${ }^{1}$ Department of Pediatrics, Seoul National University Hospital, Seoul 03080, Republic of Korea \\ ${ }^{2}$ Research Coordination Center for Rare Diseases, Seoul National University Hospital, Seoul 03080, Republic of Korea \\ ${ }^{3}$ Kidney Research Institute, Medical Research Center, Seoul National University College of Medicine, Seoul 03080, Republic of Korea \\ Correspondence should be addressed to Hae Il Cheong; cheonghi@snu.ac.kr
}

Received 25 December 2015; Revised 14 March 2016; Accepted 4 April 2016

Academic Editor: Jun Oh

Copyright ( 2016 Hee Gyung Kang et al. This is an open access article distributed under the Creative Commons Attribution License, which permits unrestricted use, distribution, and reproduction in any medium, provided the original work is properly cited.

Focal segmental glomerulosclerosis (FSGS) is a common cause of end-stage renal disease and a common pathologic diagnosis of idiopathic nephrotic syndrome (NS), especially in steroid-resistant cases. FSGS is known to recur after kidney transplantation, frequently followed by graft loss. However, not all patients with FSGS suffer from recurrence after kidney transplantation, and genetic and secondary FSGS have a negligible risk of recurrence. Furthermore, many cases of recurrence achieve remission with the current management of recurrence (intensive plasmapheresis/immunosuppression, including rituximab), and other promising agents are being evaluated. Therefore, a pathologic diagnosis of FSGS itself should not cause postponement of allograft kidney transplantation. For patients with a high risk of recurrence who presented with classical symptoms of NS, that is, severe edema, proteinuria, and hypoalbuminemia, close monitoring of proteinuria is necessary, followed by immediate, intensive treatment for recurrence.

\section{Introduction}

Focal segmental glomerulosclerosis (FSGS) is a common cause of end-stage renal disease (ESRD). In children, the major causes of ESRD are congenital anomalies of the kidney and urinary tract and hereditary nephropathies, followed by FSGS as the most common form of acquired glomerulopathies causing ESRD $[1,2]$. FSGS is the second-most common pathologic diagnosis of idiopathic nephrotic syndrome (NS) $[3,4]$. Although the majority of pediatric idiopathic NS patients respond to steroid treatment, some are resistant to treatment and eventually progress to ESRD [5], and their renal pathology often reveals FSGS. Because FSGS is known to recur after kidney transplantation, frequently followed by graft loss in up to $60 \%$ of the cases [6-9], the diagnosis of idiopathic FSGS requires a thorough discussion of its prognosis with patients and their families. However, not all patients with FSGS suffer from recurrence after kidney transplantation, and many cases of recurrence achieve remission with the current management of recurrence and enjoy life as a kidney allograft recipient for as long as the average kidney recipient
[10-12]. In this paper, the current knowledge of the risk factors for recurrence of FSGS and its treatment in children will be reviewed.

\section{Who Is at Risk of Recurrence and Who Is Not?}

The reported rates of recurrence are quite variable, from 6 to $58 \%$, depending on the characteristics of the population studied [11-14]. The suggested risk factors for recurrence include the age at onset of disease [14-16], a rapid progression to ESRD (<48-72 months) [17-21], and a history of previous recurrence in an allograft $[6,18,22]$. Pathologic characteristics of the native kidney biopsy, such as mesangial hypercellularity [23] and fewer sclerotic glomeruli $[19,20]$, and a living donor allograft [24] have also been proposed as risk factors but have not been confirmed [25]. Native kidney nephrectomy prior to kidney transplantation has been suggested by some as a preventive measure of recurrence [21, 26, 27], but it has not been effective and has even shown a higher risk 
of recurrence in other reports [10, 28, 29]. According to our experiences with 38 children with FSGS, most of those with a later onset ( $\geq 6$ yrs. old) and a progression to ESRD in the 24 72 months after onset of NS experienced recurrence, whereas those who had an earlier onset ( $<6$ yrs.) of NS with a faster progression ( $<18$ months) did not have recurrence [11]. There has been controversy over the onset age group that is at risk of recurrence; generally younger patients are considered to be at a higher risk than older patients [13], but some studies have reported no differences between adults and children [30] and even higher risks in adults than in children [25]. The main reason for these differences could be the small sample size of the study populations in most of the reports. In addition, two more aspects should be considered.

First, there are several genetic defects that cause FSGS [31-33], and the frequency and distribution of the genetic types of FSGS differ between populations. For example, the NPHS2 mutation is the dominant cause of genetic FSGS in European countries, but it is rare in Koreans and the Japanese [31, 34-36]. Although idiopathic steroid-resistant NS (SRNS) with FSGS pathology is believed to be caused by some circulating factors [37] and is therefore prone to recur after kidney transplantation, most genetic FSGS have defective components of the kidneys, particularly podocytes, and therefore their risk of recurrence is low if not zero $[16,32,36,38$ 40]. Some genetic FSGS are characterized by an early onset of SRNS; some syndromic FSGS are accompanied by extrarenal symptoms that may not be evident at the onset of SRNS, thus mimicking idiopathic SRNS. Because a genetic diagnosis of SRNS-FSGS has not yet been incorporated as a routine component of clinical practice in most parts of the world, we do not know how many of the patients previously categorized as SRNS-FSGS have genetic FSGS. In fact, some of the cases that we previously reported as idiopathic SRNS-FSGS were recently found to have mutations in COQ6 [41] (in patients with progressive hearing loss) or a newly found FSGS-causing gene NUP107 [42] (unpublished data); these patients had an earlier onset $(<6$ yrs.) of NS with a faster progression $(<18$ months) and did not have recurrence [11]. A recent report by Ding et al. showed that children with SRNS who initially responded to steroid treatment were at risk of recurrence after kidney transplantation [43]. This finding may also imply that these cases have nongenetic FSGS. In other words, the wide range of risks of recurrence found in the literature seems to have been dependent on whether genetic testing was broadly performed in the studied cohort.

Second, FSGS is a pathologic diagnosis, and there are multiple causes other than idiopathic SRNS that lead to FSGS [44]. Some of the causes are evident, such as chronic infection (e.g., HIV infection) or reflux nephropathy; however, others are not. Therefore, the distinction between "secondary" and primary (idiopathic) FSGS is not always clear. Similar to genetic FSGS, FSGS secondary to other causes does not recur after kidney transplantation if the causes no longer exist after kidney transplantation; some of the reported FSGS cases without recurrence may in fact have been secondary FSGS. In our own clinical experience, patients who presented with proteinuria but without edema did not experience recurrence; although there was no identifiable cause of FSGS and they

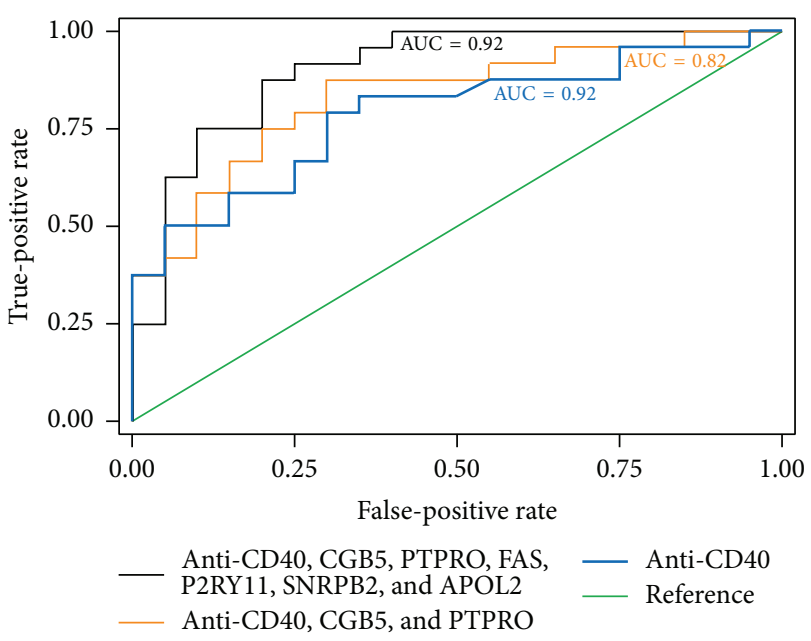

FIgURE 1: Validation of the FAST Ab panel in rFSGS and the predictive accuracy of the subsets of this panel. ROC analysis for three fitted logistic regression models. The outcome was recurrence versus nonrecurrence of FSGS, and the independent predictors were the log-transformed relative fluorescent signal values of seven Abs: CD40, PTPRO, FAS, CGB5, SNRPB2, APOL2, and P2RY11. The three logistic regression models fitted are shown. Model 1 used the FAST (FSGS antibody serological test) panel with all seven Abs, resulting in an $\mathrm{AUC}=0.9$. Model 2 used three Abs (CD40, PTPRO, and CGB5), and its ROC curve had an AUC of 0.82. Model 3 used only CD40 Ab data for the ROC analysis, resulting in an AUC of 0.77. Reproduced with permission from The American Association for the Advancement of Science (c) 2014 (AAAS), Delville et al. [45].

were therefore categorized as primary FSGS, we speculate that these cases may have had obscure causes leading to FSGS [11]. Therefore, the pathologic diagnosis of FSGS itself does not mean that the disease could recur after kidney transplantation.

\section{Are There Biomarkers Predicting Recurrence?}

Despite a decades-long search for circulating "permeability factor(s)" causing FSGS [47], these factors remain elusive [37]. When soluble urokinase receptor (suPAR) was reported to be a candidate permeability factor [48], this news was met with excitement. However, contradicting reports followed [49], and therefore the usefulness of suPAR as a biomarker predicting recurrence is currently doubted. Cardiotrophinlike 1 (CLC-1) is another candidate that has been proposed by Savin's group [50] and is awaiting validation. Similar to other circulating factors, autoantibodies including antiCD40 antibody have been proposed that have shown a good predictive accuracy of recurrence (Figure 1), but these candidates require further validation in clinical trials [45]. Another approach to identifying biomarkers is the assessment of podocyte changes in response to suspicious factor(s). Vasodilator-stimulated phosphoprotein (VASP) in human podocytes has been shown to be phosphorylated in response to plasma from patients with posttransplant recurrence but not to plasma from non-FSGS, and genetic FSGS cases did not 


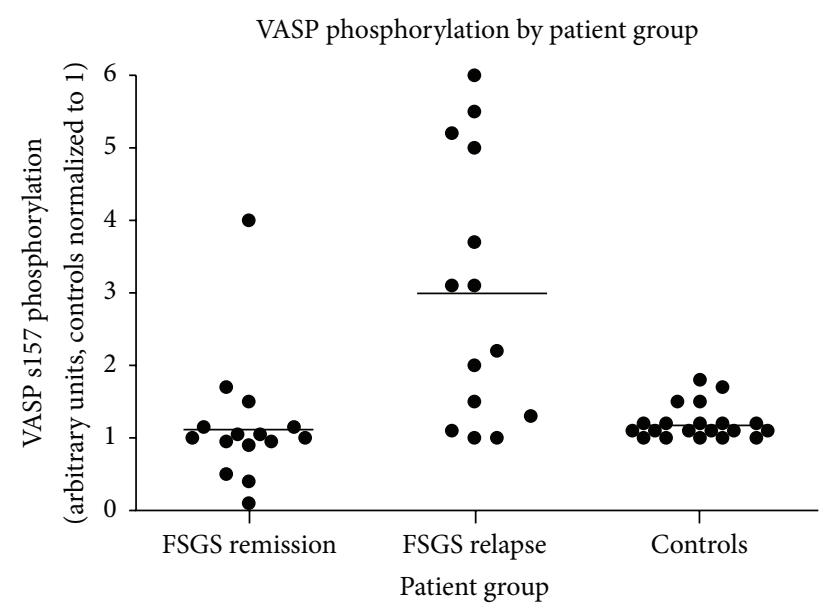

FIGURE 2: Scatter plot of VASP phosphorylation levels by patient group. Phosphorylation for each individual sample was assigned a densitometry value relative to the control (normal) plasma sample from the same gel, which was normalized to 1 . Reproduced with permission from Wiley (C) 2012 Pathological Society of Great Britain and Ireland, Harris et al. [46].

show this effect on podocytes (Figure 2). Once these promising biomarkers are validated and incorporated into clinical practice, we will be able to better predict whether recurrence will occur in a certain patient after kidney transplantation [46]. This would enable us to properly evaluate the efficacy of prophylactic management such as prophylactic plasmapheresis/immunoadsorption or immunosuppression and to possibly conduct preventive measures before transplantation [9].

\section{How to Treat Recurrence}

Although the recurrence of FSGS is a significant risk factor of graft loss [24, 29, 30, 51, 52], the outcomes of recurrent FSGS have so much improved that primary FSGS is no longer considered a contraindication of transplantation. The remission rate of pediatric recurrent FSGS has been reported to be as high as $70 \%[11,12]$. The mainstay of treatment for recurrent FSGS is plasmapheresis (removing 1.5 plasma volumes with $5 \%$ albumin replacement)/immunoadsorption because recurrence is believed to be caused by circulating factor(s) [53-55]. There have been no prospective randomized clinical trials to compare the efficacies of plasmapheresis and immunoadsorption, and the outcomes of studies using either method seem similar; therefore, the choice between these two methods depends on their availability and the preference of the treating physician [55-57]. It is important to begin treatment as soon as possible because removal or replacement of the FSGS-causing circulating factor(s) should be instituted before irreversible damage can be inflicted to the glomeruli [58]. While there is no evidence that anuric status at the time of transplantation prevents recurrence, recurrence can be detected more promptly if the patient had been anuric, and therefore native kidney nephrectomy can be considered in patients with residual urine output. Once the factors are removed, maintenance immunosuppression against graft rejection would also suppress the resurgence of the source of FSGS. It seems that, for some patients, plasmapheresis/immunoadsorption is sufficient to induce remission of recurrent FSGS $[55,59]$. For others, intense immunosuppression with high-dose methylprednisolone, cyclosporine [12], cyclophosphamide [9], or rituximab [60] at various combinations is necessary. Although high-dose cyclosporine has been advocated as necessary by some $[9,12]$ and tacrolimus as a replacement for cyclosporine has been questioned [9], in our own clinical experience, tacrolimus trough levels of 12 to $15 \mathrm{ng} / \mathrm{mL}$ in combination with high-dose methylprednisolone and rituximab in addition to immediate and intense plasmapheresis have worked well, achieving remission in more than $80 \%$ of recent recurrent cases (unpublished data). The addition of rituximab to the current strategy against recurrent FSGS seems beneficial, demonstrating a response rate of up to $79 \%$ in recurrent FSGS [60, 61]. Although the optimal dosage $\left(375 \mathrm{mg} / \mathrm{m}^{2}\right.$ up to 6 doses or a single dose of $100 \mathrm{mg}$ [62]) and mechanism of action (eradication of B lymphocytes or binding to sphingomyelin phosphodiesterase acid-like 3b [SMPDL-3b] on podocytes [63]) of this medication remain elusive, a single dose or two of $375 \mathrm{mg} / \mathrm{m}^{2}$ rituximab have been satisfactory in achieving sustained complete remission in our practice (Figure 3 ).

There are several promising therapeutic agents that are awaiting validation. Cytotoxic T-lymphocyte-associated antigen 4-immunoglobulin fusion protein (CTLD4-Ig, abatacept) has been tested on the basis that B7-1 (CD80) induction on podocytes plays an important role in the pathogenesis of proteinuria [64] and could eradicate proteinuria in recurrent FSGS [65]; however, the long-term efficacy of this agent has not been confirmed [66]. Of note, another form of CTLA4-Ig, belatacept, is being evaluated as a long-acting maintenance immunosuppressant against kidney allograft rejection [67]. CTLA4-Ig, a costimulatory inhibitor that competes with B7-1, could be indicated in the suppression of both allograft rejection and proteinuria. However, belatacept has been shown to increase the risk of posttransplant lymphoproliferative disease in Epstein-Barr virus- (EBV-) naïve patients [68]. Because the majority of pediatric recipients are naive to EBV infection, caution is warranted when considering CTLA4-Ig as a therapeutic agent against recurrent FSGS in children. Another agent of interest is galactose. In the search for a "permeability factor" causing FSGS, galactose was found to bind to the factor(s) and eliminate their proteinuric effect $[69,70]$. In addition to the clinical trials of this agent in pediatric SRNS $[71,72]$, anecdotal cases of significant improvement have been reported in recurrent FSGS [73, 74]. Successful treatment of recurrent FSGS has also been reported with anti-TNF- $\alpha$ treatment [75] (based on the upregulation of TNF- $\alpha$ mRNA in patients with FSGS [76]), adrenocorticotrophic hormone gel [77], and allogeneic mesenchymal stem cells [78, 79].

An important point is that treatment failure on native kidneys does not predict treatment failure for posttransplantation recurrence of FSGS. Why? For recurrent FSGS after transplantation, we start treatment almost immediately, before the formation of sclerosis. This implies that delays in treating the native kidney lead to treatment failure, resulting in progressive renal damage. Therefore, if we are equipped 


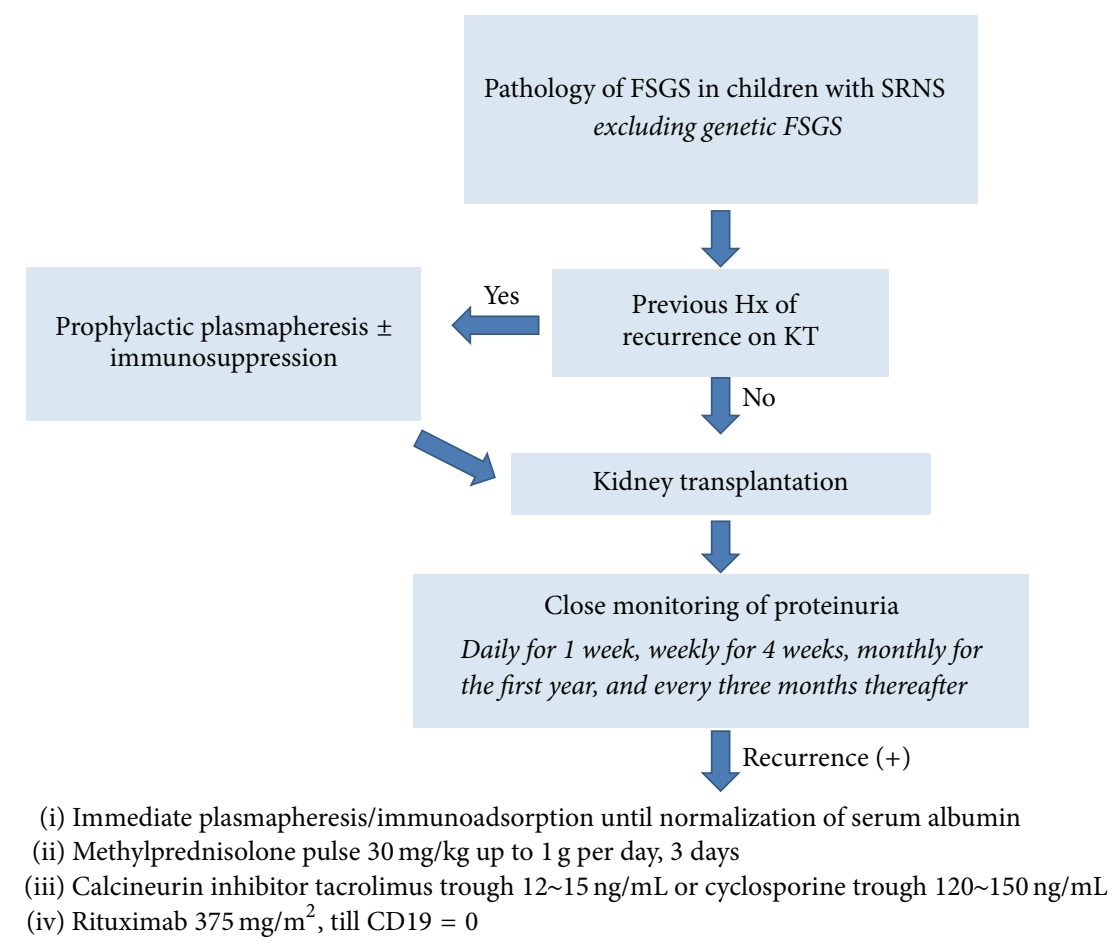

FIGURE 3: Approach for patients with SRNS-FSGS, authors' suggestion.

with reliable biomarkers that indicate which medications will be effective in specific patients at the time of NS diagnosis, we will be able to tailor the treatment of pediatric NS, thus applying "precision medicine" to these patients.

\section{How to Prevent Recurrence}

While any discussion of preventive treatments efficacy is futile because we do not know whether subjects will experience recurrence after transplantation, patients who had lost their previous allograft to recurrence of FSGS have particularly high risk of recurrence $[6,18,22]$. For these patients, to eliminate circulating factors, preemptive plasmapheresis/immunoadsorption is considered, three to five sessions prior to the transplantation followed by immediate posttransplant sessions of three to five [80-85]. Additional single dose of rituximab $\left(375 \mathrm{mg} / \mathrm{m}^{2}\right)$ along with immunosuppression of corticosteroid, calcineurin inhibitor, and mycophenolate mofetil for two weeks prior to kidney transplantation was shown to prevent recurrence $[81,84]$.

\section{Conclusion}

Recurrence after kidney transplantation is devastating for patients and families. However, the outcomes of recurrent FSGS are quite good with the current management strategy; therefore, the pathologic diagnosis of FSGS itself should not be a cause for postponing allograft kidney transplantation. For patients with a high risk of recurrence, close monitoring of proteinuria as suggested by the Kidney Disease: Improving Global Outcomes guidelines for the management of kidney transplant recipients [86] is necessary, followed by immediate, intensive treatment for recurrence, as suggested in Figure 3.

\section{Competing Interests}

The authors declare that there are no competing interests regarding the publication of this paper.

\section{Acknowledgments}

This study was supported by a grant (HI12C0014) from the Korean Health Technology R\&D Project, Ministry of Health $\&$ Welfare, Republic of Korea.

\section{References}

[1] J. Kari, "Epidemiology of chronic kidney disease in children," Journal of Nephropathology, vol. 1, no. 3, pp. 162-163, 2012.

[2] J. Harambat, K. J. van Stralen, J. J. Kim, and E. J. Tizard, "Epidemiology of chronic kidney disease in children," Pediatric Nephrology, vol. 27, no. 3, pp. 363-373, 2012.

[3] M. Mubarak, J. I. Kazi, A. Lanewala, S. Hashmi, and F. Akhter, "Pathology of idiopathic nephrotic syndrome in children: are the adolescents different from young children?" Nephrology Dialysis Transplantation, vol. 27, no. 2, pp. 722-726, 2012.

[4] D. S. Gipson, J. P. Troost, R. A. Lafayette et al., "Complete remission in the nephrotic syndrome study network," Clinical Journal of the American Society of Nephrology, vol. 11, no. 1, pp. 81-89, 2016. 
[5] D. Mekahli, A. Liutkus, B. Ranchin et al., "Long-term outcome of idiopathic steroid-resistant nephrotic syndrome: a multicenter study," Pediatric Nephrology, vol. 24, no. 8, pp. 1525-1532, 2009.

[6] P. Cochat, S. Fargue, G. Mestrallet et al., "Disease recurrence in paediatric renal transplantation," Pediatric Nephrology, vol. 24, no. 11, pp. 2097-2108, 2009.

[7] K. J. Van Stralen, E. Verrina, M. Belingheri et al., "Impact of graft loss among kidney diseases with a high risk of post-transplant recurrence in the paediatric population," Nephrology Dialysis Transplantation, vol. 28, no. 4, pp. 1031-1038, 2013.

[8] G. Canaud, M. Delville, and C. Legendre, "Recurrence of focal and segmental glomerulosclerosis after transplantation," Transplantation, vol. 100, no. 2, pp. 284-287, 2016.

[9] J. Bacchetta and P. Cochat, "Primary disease recurrence-effects on paediatric renal transplantation outcomes," Nature Reviews Nephrology, vol. 11, no. 6, pp. 371-384, 2015.

[10] A. Sener, A. J. Bella, C. Nguan, P. P. W. Luke, and A. A. House, "Focal segmental glomerular sclerosis in renal transplant recipients: predicting early disease recurrence may prolong allograft function," Clinical Transplantation, vol. 23, no. 1, pp. 96-100, 2009.

[11] S. E. Lee, S. I. Min, Y. S. Kim et al., "Recurrence of idiopathic focal segmental glomerulosclerosis after kidney transplantation: experience of a Korean tertiary center," Pediatric Transplantation, vol. 18, no. 4, pp. 369-376, 2014.

[12] S. Shishido, H. Satou, M. Muramatsu et al., "Combination of pulse methylprednisolone infusions with cyclosporine-based immunosuppression is safe and effective to treat recurrent focal segmental glomerulosclerosis after pediatric kidney transplantation," Clinical Transplantation, vol. 27, no. 2, pp. E143-E150, 2013.

[13] K. Huang, M. E. Ferris, K. A. Andreoni, and D. S. Gipson, "The differential effect of race among pediatric kidney transplant recipients with focal segmental glomerulosclerosis," American Journal of Kidney Diseases, vol. 43, no. 6, pp. 1082-1090, 2004.

[14] L. J. Hickson, M. Gera, H. Amer et al., "Kidney transplantation for primary focal segmental glomerulosclerosis: outcomes and response to therapy for recurrence," Transplantation, vol. 87, no. 8, pp. 1232-1239, 2009.

[15] E. Ingulli and A. Tejani, "Incidence, treatment, and outcome of recurrent focal segmental glomerulosclerosis posttransplantation in 42 allografts in children-a single-center experience," Transplantation, vol. 51, no. 2, pp. 401-405, 1991.

[16] R. J. H. Maas, J. K. J. Deegens, J. A. J. G. van den Brand, E. A. M. Cornelissen, and J. F. M. Wetzels, "A retrospective study of focal segmental glomerulosclerosis: clinical criteria can identify patients at high risk for recurrent disease after first renal transplantation," BMC Nephrology, vol. 14, article 47, 2013.

[17] A. Tejani and D. H. Stablein, "Recurrence of focal segmental glomerulosclerosis posttransplantation: a special report of the North American pediatric renal transplant cooperative study," Journal of the American Society of Nephrology, vol. 2, supplement, no. 12, pp. S258-S263, 1992.

[18] R. Dall'Amico, G. Ghiggeri, M. Carraro et al., "Prediction and treatment of recurrent focal segmental glomerulosclerosis after renal transplantation in children," American Journal of Kidney Diseases, vol. 34, no. 6, pp. 1048-1055, 1999.

[19] H. Cheong II, H. W. Han, H. W. Park et al., "Early recurrent nephrotic syndrome after renal transplantation in children with focal segmental glomerulosclerosis," Nephrology Dialysis Transplantation, vol. 15, no. 1, pp. 78-81, 2000.
[20] S. J. Kim, J. Ha, I. M. Jung et al., "Recurrent focal segmental glomerulosclerosis following renal transplantation in Korean pediatric patients," Pediatric Transplantation, vol. 5, no. 2, pp. 105-111, 2001.

[21] M. Fujisawa, K. Iijima, T. Ishimura et al., "Long-term outcome of focal segmental glomerulosclerosis after Japanese pediatric renal transplantation," Pediatric Nephrology, vol. 17, no. 3, pp. 165-168, 2002.

[22] J. T. Crosson, "Focal segmental glomerulosclerosis and renal transplantation," Transplantation Proceedings, vol. 39, no. 3, pp. 737-743, 2007.

[23] J. Dantal, R. Baatard, M. Hourmant, D. Cantarovich, F. Buzelin, and J. P. Soulillou, "Recurrent nephrotic syndrome following renal transplantation in patients with focal glomerulosclerosis: a one-center study of plasma exchange effects," Transplantation, vol. 52, no. 5, pp. 827-831, 1991.

[24] M. A. Baum, "Outcomes after renal transplantation for FSGS in children," Pediatric Transplantation, vol. 8, no. 4, pp. 329-333, 2004.

[25] E. J. Nehus, J. W. Goebel, P. S. Succop, and E. C. Abraham, "Focal segmental glomerulosclerosis in children: multivariate analysis indicates that donor type does not alter recurrence risk," Transplantation, vol. 96, no. 6, pp. 550-554, 2013.

[26] F. P. Stuart, "Selection, preparation, and management of kidney transplant recipients," Medical Clinics of North America, vol. 62, no. 6, pp. 1381-1397, 1978.

[27] "The 13th report of the human renal transplant registry," Transplantation Proceedings, vol. 9, no. 1, pp. 9-26, 1977.

[28] J. S. Odorico, S. J. Knechtle, S. C. Rayhill et al., “The influence of native nephrectomy on the incidence of recurrent disease following renal transplantation for primary glomerulonephritis," Transplantation, vol. 61, no. 2, pp. 228-234, 1996.

[29] G. M. Cara Fuentes, C. Garcia Meseguer, A. Pena Carrion et al., "Long-term outcome of focal segmental glomerulosclerosis after pediatric renal transplantation," Pediatric Nephrology, vol. 25, no. 3, pp. 529-534, 2010.

[30] J. H. Hwang, S. S. Han, W. Huh et al., "Outcome of kidney allograft in patients with adulthood-onset focal segmental glomerulosclerosis: comparison with childhood-onset FSGS," Nephrology Dialysis Transplantation, vol. 27, no. 6, pp. 25592565, 2012.

[31] C. E. Sadowski, S. Lovric, S. Ashraf et al., "A single-gene cause in $29.5 \%$ of cases of steroid-resistant nephrotic syndrome," Journal of the American Society of Nephrology, vol. 26, no. 6, pp. 12791289, 2015.

[32] S. Giglio, A. Provenzano, B. Mazzinghi et al., "Heterogeneous genetic alterations in sporadic nephrotic syndrome associate with resistance to immunosuppression," Journal of the American Society of Nephrology, vol. 26, no. 1, pp. 230-236, 2015.

[33] A. Trautmann, M. Bodria, F. Ozaltin et al., "Spectrum of steroidresistant and congenital nephrotic syndrome in children: the podoNet registry cohort," Clinical Journal of the American Society of Nephrology, vol. 10, no. 4, pp. 592-600, 2015.

[34] A. Kitamura, H. Tsukaguchi, K. Iijima et al., "Genetics and clinical features of 15 Asian families with steroid-resistant nephrotic syndrome," Nephrology Dialysis Transplantation, vol. 21, no. 11, pp. 3133-3138, 2006.

[35] J. H. Lee, K. H. Han, H. Lee et al., "Genetic basis of congenital and infantile nephrotic syndromes," American Journal of Kidney Diseases, vol. 58, no. 6, pp. 1042-1043, 2011. 
[36] S. Santín, B. Tazón-Vega, I. Silva et al., "Clinical value of NPHS2 analysis in early- and adult-onset steroid-resistant nephrotic syndrome," Clinical Journal of the American Society of Nephrology, vol. 6, no. 2, pp. 344-354, 2011.

[37] T. Wada and M. Nangaku, "A circulating permeability factor in focal segmental glomerulosclerosis: the hunt continues," Clinical Kidney Journal, vol. 8, no. 6, pp. 708-715, 2015.

[38] S. Weber, O. Gribouval, E. L. Esquivel et al., "NPHS2 mutation analysis shows genetic heterogeneity of steroid-resistant nephrotic syndrome and low post-transplant recurrence," Kidney International, vol. 66, no. 2, pp. 571-579, 2004.

[39] T. Ulinski, "Recurrence of focal segmental glomerulosclerosis after kidney transplantation: strategies and outcome," Current Opinion in Organ Transplantation, vol. 15, no. 5, pp. 628-632, 2010.

[40] S. Weber and B. Tönshoff, "Recurrence of focal-segmental glomerulosclerosis in children after renal transplantation: clinical and genetic aspects," Transplantation, vol. 80, supplement, no. 1, pp. S128-S134, 2005.

[41] S. F. Heeringa, G. Chernin, M. Chaki et al., "COQ6 mutations in human patients produce nephrotic syndrome with sensorineural deafness," The Journal of Clinical Investigation, vol. 121, no. 5, pp. 2013-2024, 2011.

[42] N. Miyake, H. Tsukaguchi, E. Koshimizu et al., "Biallelic mutations in nuclear pore complex subunit NUP107 cause early-childhood-onset steroid-resistant nephrotic syndrome," The American Journal of Human Genetics, vol. 97, no. 4, pp. 555566, 2015.

[43] W. Y. Ding, A. Koziell, H. J. McCarthy et al., "Initial steroid sensitivity in children with steroid-resistant nephrotic syndrome predicts post-transplant recurrence," Journal of the American Society of Nephrology, vol. 25, no. 6, pp. 1342-1348, 2015.

[44] A. B. Fogo, "Causes and pathogenesis of focal segmental glomerulosclerosis," Nature Reviews Nephrology, vol. 11, no. 2, pp. 76-87, 2015.

[45] M. Delville, T. K. Sigdel, C. Wei et al., "A circulating antibody panel for pretransplant prediction of FSGS recurrence after kidney transplantation," Science Translational Medicine, vol. 6, no. 256, Article ID 256ra136, 2014.

[46] J. J. Harris, H. J. McCarthy, L. Ni et al., "Active proteases in nephrotic plasma lead to a podocin-dependent phosphorylation of VASP in podocytes via protease activated receptor-1," The Journal of Pathology, vol. 229, no. 5, pp. 660-671, 2013.

[47] R. J. Maas, J. K. Deegens, and J. F. Wetzels, "Permeability factors in idiopathic nephrotic syndrome: historical perspectives and lessons for the future," Nephrology Dialysis Transplantation, vol. 29, no. 12, pp. 2207-2216, 2014.

[48] C. Wei, S. El Hindi, J. Li et al., "Circulating urokinase receptor as a cause of focal segmental glomerulosclerosis," Nature Medicine, vol. 17, no. 8, pp. 952-960, 2011.

[49] J. M. Spinale, L. H. Mariani, S. Kapoor et al., "A reassessment of soluble urokinase-type plasminogen activator receptor in glomerular disease," Kidney International, vol. 87, no. 3, pp. 564574, 2015.

[50] M. Sharma, J. Zhou, J.-F. Gauchat et al., "Janus kinase 2/signal transducer and activator of transcription 3 inhibitors attenuate the effect of cardiotrophin-like cytokine factor 1 and human focal segmental glomerulosclerosis serum on glomerular filtration barrier," Translational Research, vol. 166, no. 4, pp. 384-398, 2015.

[51] M. A. Baum, D. M. Stablein, V. M. Panzarino, A. Tejani, W. E. Harmon, and S. R. Alexander, "Loss of living donor renal allograft survival advantage in children with focal segmental glomerulosclerosis," Kidney International, vol. 59, no. 1, pp. 328333, 2001.

[52] M. Vinai, P. Waber, and M. G. Seikaly, "Recurrence of focal segmental glomerulosclerosis in renal allograft: an in-depth review," Pediatric Transplantation, vol. 14, no. 3, pp. 314-325, 2010.

[53] V. J. Savin, R. Sharma, M. Sharma et al., "Circulating factor associated with increased glomerular permeability to albumin in recurrent focal segmental glomerulosclerosis," The New England Journal of Medicine, vol. 334, no. 14, pp. 878-883, 1996.

[54] E. T. McCarthy, M. Sharma, and V. J. Savin, "Circulating permeability factors in idiopathic nephrotic syndrome and focal segmental glomerulosclerosis," Clinical Journal of the American Society of Nephrology, vol. 5, no. 11, pp. 2115-2121, 2010.

[55] C. Straatmann, M. Kallash, M. Killackey et al., "Success with plasmapheresis treatment for recurrent focal segmental glomerulosclerosis in pediatric renal transplant recipients," Pediatric Transplantation, vol. 18, no. 1, pp. 29-34, 2014.

[56] F. Fencl, E. Šimková, K. Vondrák et al., "Recurrence of nephrotic proteinuria in children with focal segmental glomerulosclerosis after renal transplantation treated with plasmapheresis and immunoadsorption: case reports," Transplantation Proceedings, vol. 39, no. 10, pp. 3488-3490, 2007.

[57] F. Fencl, K. Vondrak, T. Rosik et al., "Recurrence of nephrotic proteinuria in children with focal segmental glomerulosclerosis-early treatment with plasmapheresis and immunoadsorption should be associated with better prognosis," Minerva Pediatrica, In press.

[58] G. Canaud, D. Dion, J. Zuber et al., "Recurrence of nephrotic syndrome after transplantation in a mixed population of children and adults: course of glomerular lesions and value of the columbia classification of histological variants of focal and segmental glomerulosclerosis (FSGS)," Nephrology Dialysis Transplantation, vol. 25, no. 4, pp. 1321-1328, 2010.

[59] C. Ponticelli, "Recurrence of focal segmental glomerular sclerosis (FSGS) after renal transplantation," Nephrology Dialysis Transplantation, vol. 25, no. 1, pp. 25-31, 2010.

[60] R. Trachtman, S. S. Sran, and H. Trachtman, "Recurrent focal segmental glomerulosclerosis after kidney transplantation," Pediatric Nephrology, vol. 30, no. 10, pp. 1793-1802, 2015.

[61] C. E. Araya and V. R. Dharnidharka, "The factors that may predict response to rituximab therapy in recurrent focal segmental glomerulosclerosis: a systematic review," Journal of Transplantation, vol. 2011, Article ID 374213, 7 pages, 2011.

[62] J.-H. Cho, J.-H. Lee, G.-Y. Park et al., "Successful treatment of recurrent focal segmental glomerulosclerosis with a low dose rituximab in a kidney transplant recipient," Renal Failure, vol. 36, no. 4, pp. 623-626, 2014.

[63] A. Fornoni, J. Sageshima, C. Wei et al., "Rituximab targets podocytes in recurrent focal segmental glomerulosclerosis," Science Translational Medicine, vol. 3, no. 85, Article ID 85ra46, 2011.

[64] P. Mundel and J. Reiser, "Proteinuria: an enzymatic disease of the podocyte," Kidney International, vol. 77, no. 7, pp. 571-580, 2010.

[65] C.-C. Yu, A. Fornoni, A. Weins et al., "Abatacept in B7-1positive proteinuric kidney disease," The New England Journal of Medicine, vol. 369, no. 25, pp. 2416-2423, 2013.

[66] E. H. Garin, J. Reiser, G. Cara-Fuentes et al., "Case series: CTLA4-IgG1 therapy in minimal change disease and focal 
segmental glomerulosclerosis," Pediatric Nephrology, vol. 30, no. 3, pp. 469-477, 2014.

[67] L. Rostaing, P. Massari, V. D. Garcia et al., "Switching from calcineurin inhibitor-based regimens to a belatacept-based regimen in renal transplant recipients: a randomized phase II study," Clinical Journal of the American Society of Nephrology, vol. 6, no. 2, pp. 430-439, 2011.

[68] H. Wéclawiak, N. Kamar, A. Ould-Mohamed, I. CardeauDesangles, and L. Rostaing, "Biological agents in kidney transplantation: belatacept is entering the field," Expert Opinion on Biological Therapy, vol. 10, no. 10, pp. 1501-1508, 2010.

[69] E. De Smet, J.-P. Rioux, H. Ammann, C. Déziel, and S. Quérin, "FSGS permeability factor-associated nephrotic syndrome: remission after oral galactose therapy," Nephrology Dialysis Transplantation, vol. 24, no. 9, pp. 2938-2940, 2009.

[70] V. J. Savin, E. T. McCarthy, R. Sharma, D. Charba, and M. Sharma, "Galactose binds to focal segmental glomerulosclerosis permeability factor and inhibits its activity," Translational Research, vol. 151, no. 6, pp. 288-292, 2008.

[71] K. Sgambat, M. Banks, and A. Moudgil, "Effect of galactose on glomerular permeability and proteinuria in steroid-resistant nephrotic syndrome," Pediatric Nephrology, vol. 28, no. 11, pp. 2131-2135, 2013.

[72] H. Trachtman and V. J. Savin, "Galactose treatment in focal segmental glomerulosclerosis," Pediatric Nephrology, vol. 29, no. 5, p. 931, 2014.

[73] K. Robson, P. Hill, D. Langsford, K. Dwyer, D. Goodman, and R. Langham, "Galactose therapy reduces proteinuria in patients with recurrent focal segmental glomerulosclerosis after kidney transplantation," Nephrology, vol. 20, supplement 1, pp. 13-16, 2015.

[74] K. D. Jhaveri, T. H. Naber, X. Wang et al., "Treatment of recurrent focal segmental glomerular sclerosis posttransplant with a multimodal approach including high-galactose diet and oral galactose supplementation," Transplantation, vol. 91, no. 6, pp. e35-e36, 2011.

[75] S. Leroy, V. Guigonis, D. Bruckner et al., "Successful anti-TNF $\alpha$ treatment in a child with posttransplant recurrent focal segmental glomerulosclerosis," American Journal of Transplantation, vol. 9, no. 4, pp. 858-861, 2009.

[76] A. Bakr, M. Shokeir, F. El-Chenawi, F. El-Husseni, A. AbdelRahman, and R. El-Ashry, "Tumor necrosis factor-alpha production from mononuclear cells in nephrotic syndrome," Pediatric Nephrology, vol. 18, no. 6, pp. 516-520, 2003.

[77] T. Mittal, P. Dedhia, P. Roy-Chaudhury et al., "Complete remission of post-transplantation recurrence of focal segmental glomerulosclerosis with the use of adrenocorticotrophic hormone gel: case report," Transplantation Proceedings, vol. 47, no. 7, pp. 2219-2222, 2015.

[78] M. Belingheri, L. Lazzari, V. Parazzi et al., "Allogeneic mesenchymal stem cell infusion for the stabilization of focal segmental glomerulosclerosis," Biologicals, vol. 41, no. 6, pp. 439-445, 2013.

[79] A. V. Vanikar, H. L. Trivedi, P. R. Shah et al., "Single-center experience on renal transplantation in primary focal and segmental glomerulosclerosis using hematopoietic stem cell transplantation in thymus, bone marrow, portal and peripheral circulation," Saudi Journal of Kidney Diseases and Transplantation, vol. 24, no. 1, pp. 15-21, 2013.

[80] H. Chikamoto, M. Hattori, N. Kuroda et al., "Pretransplantation combined therapy with plasmapheresis and rituximab in a second living-related kidney transplant pediatric recipient with a very high risk for focal segmental glomerulosclerosis recurrence," Pediatric Transplantation, vol. 16, no. 7, pp. E286E290, 2012.

[81] V. Audard, N. Kamar, D. Sahali et al., "Rituximab therapy prevents focal and segmental glomerulosclerosis recurrence after a second renal transplantation," Transplant International, vol. 25, no. 5, pp. e62-e66, 2012.

[82] K. Couloures, S. H. Pepkowitz, D. Goldfinger, E. S. Kamil, and D. P. Puliyanda, "Preventing recurrence of focal segmental glomerulosclerosis following renal transplantation: a case report," Pediatric Transplantation, vol. 10, no. 8, pp. 962-965, 2006.

[83] R. Y. Gohh, A. F. Yango, P. E. Morrissey et al., "Preemptive plasmapheresis and recurrence of FSGS in high-risk renal transplant recipients," American Journal of Transplantation, vol. 5, no. 12, pp. 2907-2912, 2005.

[84] T. N. Meyer, F. Thaiss, and R. A. K. Stahl, "Immunoadsorbtion and rituximab therapy in a second living-related kidney transplant patient with recurrent focal segmental glomerulosclerosis," Transplant International, vol. 20, no. 12, pp. 1066-1071, 2007.

[85] T. Ohta, H. Kawaguchi, M. Hattori et al., "Effect of pre- and postoperative plasmapheresis on posttransplant recurrence of focal segmental glomerulosclerosis in children," Transplantation, vol. 71, no. 5, pp. 628-633, 2001.

[86] B. L. Kasiske, M. G. Zeier, J. R. Chapman et al., "KDIGO clinical practice guideline for the care of kidney transplant recipients: a summary," Kidney International, vol. 77, no. 4, pp. 299-311, 2010. 


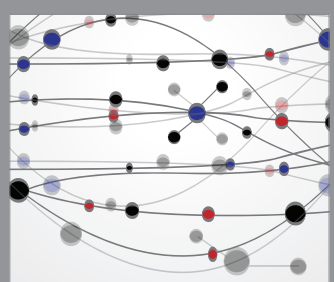

The Scientific World Journal
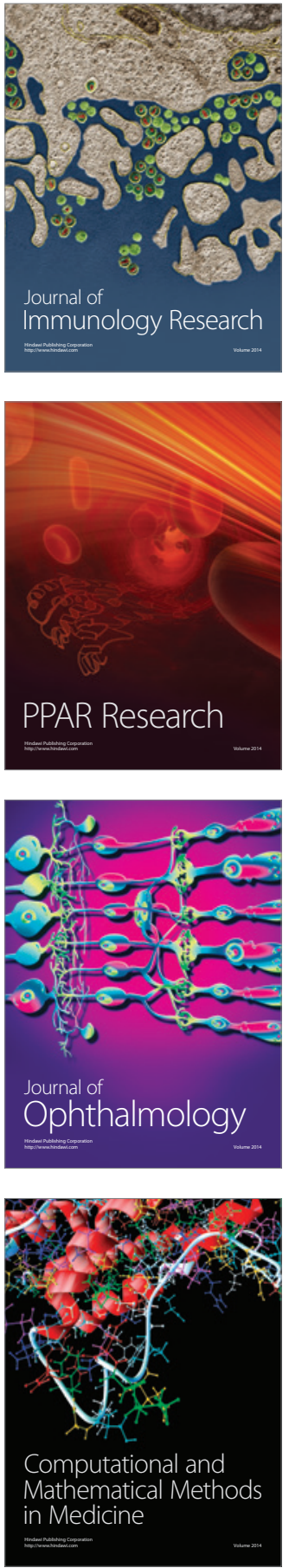

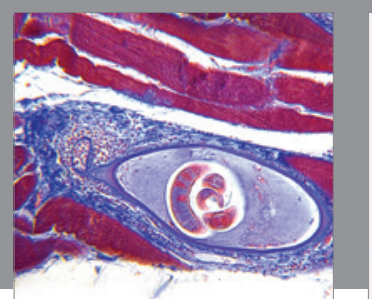

Gastroenterology Research and Practice

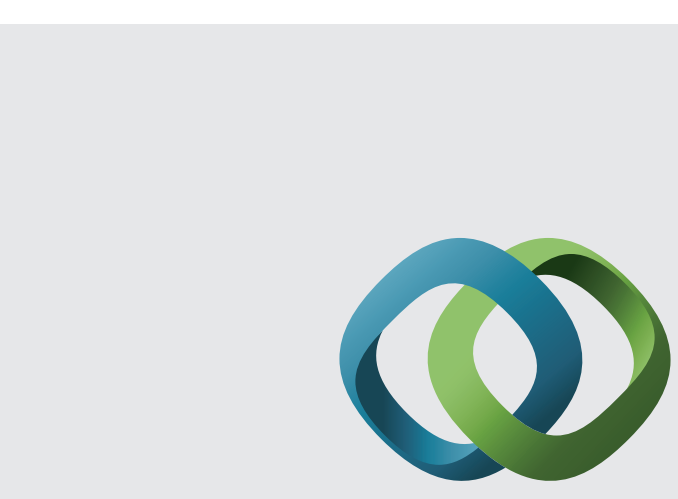

\section{Hindawi}

Submit your manuscripts at

http://www.hindawi.com
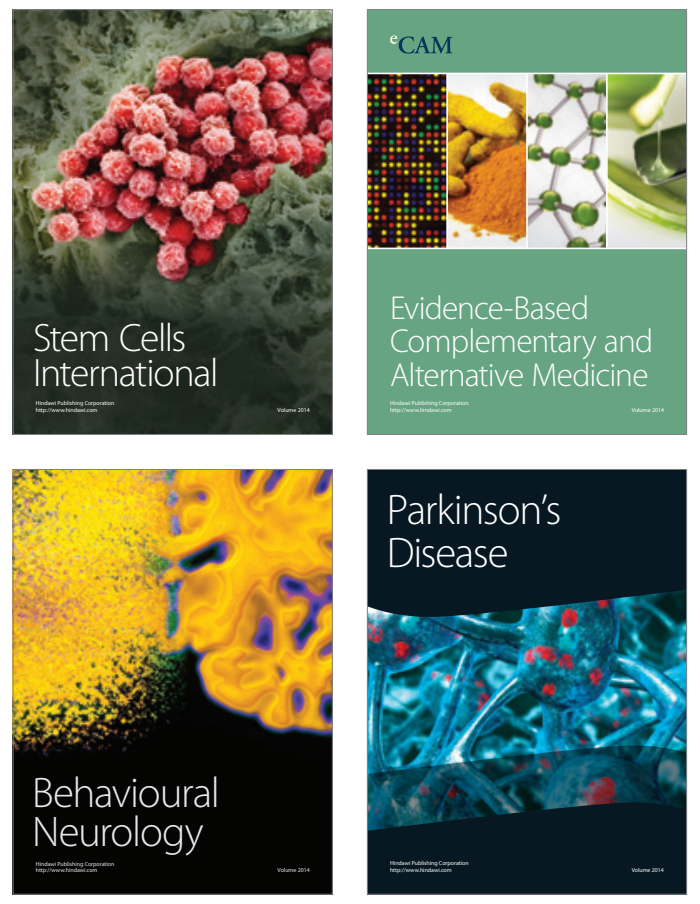
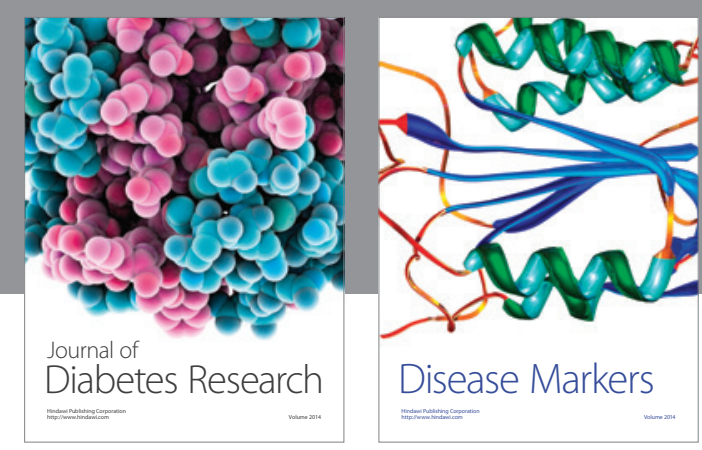

Disease Markers
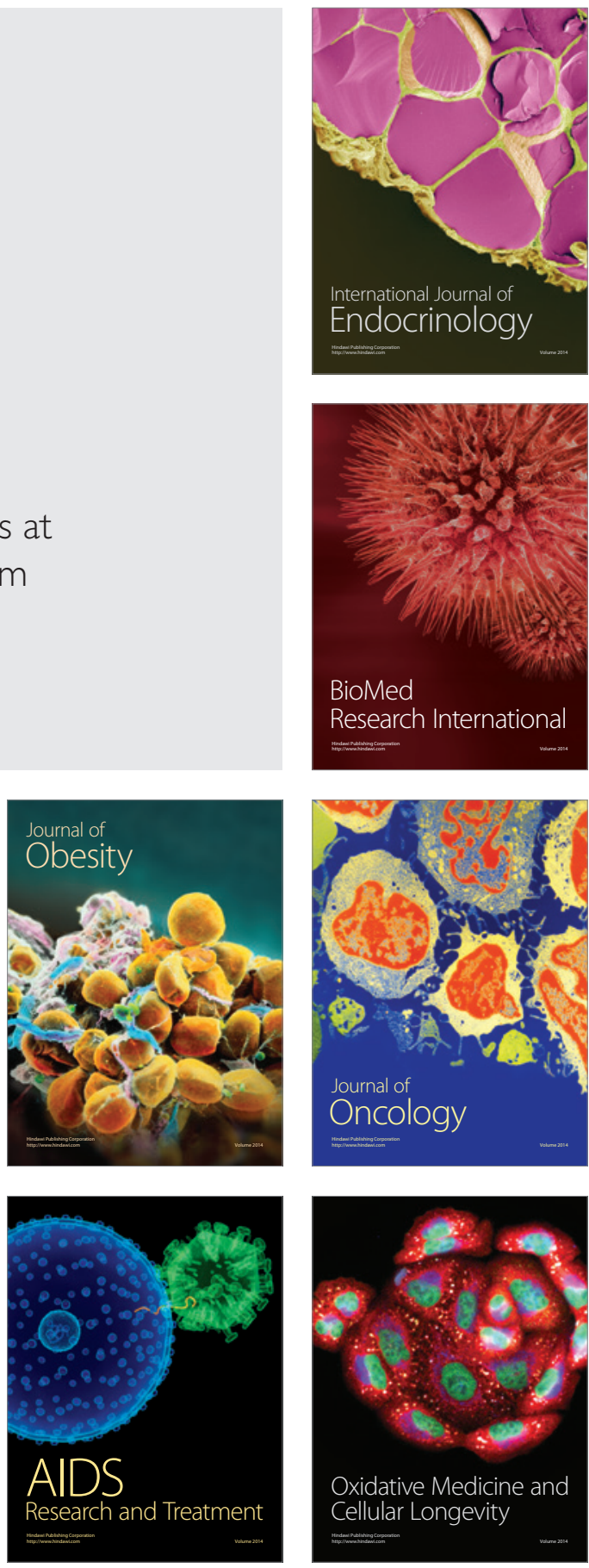